Research Article

\title{
The Construction Countermeasures of Shallow-Buried Small Spacing Tunnel Undercrossing Cultural Relic Buildings: A Case Study
}

\author{
Li Wan, ${ }^{1}$ Jiajia Shen, ${ }^{1}$ Changan Zhang, ${ }^{1}$ Zanquan Lin $\left(\mathbb{D},{ }^{2}\right.$ and Hu Zhang ${ }^{2}$ \\ ${ }^{1}$ Shandong Provincial Communications Planning and Design Institute Group Co., Ltd., Jinan 250031, China \\ ${ }^{2}$ School of Civil Engineering, Central South University, Changsha, China \\ Correspondence should be addressed to Zanquan Lin; 204811092@csu.edu.cn
}

Received 14 October 2021; Accepted 25 November 2021; Published 18 December 2021

Academic Editor: Yu Liang

Copyright (C) $2021 \mathrm{Li}$ Wan et al. This is an open access article distributed under the Creative Commons Attribution License, which permits unrestricted use, distribution, and reproduction in any medium, provided the original work is properly cited.

Based on the background of the reconstruction project from Changqing Chenzhuang-Pingyin section of G220 east-deep line in China, a special tunnel structure and construction plan was carried out according to the construction measures of the shallowburied small spacing tunnel passing underneath cultural relic buildings, and a comprehensive deformation control scheme of "CRD construction method single-arm excavation + surface grouting prereinforcement + advanced large pipe shed presupport" was put forward. The results of numerical simulation and on-site construction monitoring showed that the overall deformation of aqueduct foundation generally increases first, then decreases and increases again, and finally tends to be stable. The effects of surface grouting prereinforcement and advance large pipe shed presupport are obvious. The comprehensive deformation control scheme can ensure the safety of the existing construction and meet the safety prevention and control requirements.

\section{Introduction}

With the increasing urban traffic pressure and the saturation of existing road traffic, urban underground transportation has become the main way to relieve traffic pressure. Due to the influence of the surrounding buildings, the construction of urban underground transportation projects will inevitably encounter existing buildings (structures) such as cultural relics which are often extremely sensitive to stratum deformation. As a result, various types of proximity construction, such as the penetration of new projects, are faced with stringent control requirements $[1,2]$.

As for the underpass construction of nearby existing sensitive buildings, domestic and foreign scholars have carried out a wealth of research work in the field monitoring $[3,4]$, numerical simulation $[1,5,6]$, theoretical analysis [7-10], and other aspects. For example, Wang [11] studied the advantages and disadvantages of the underpassing scheme of jacking frame culvert and the underpassing scheme of shallow-buried tunnels in the project of Shanxi Yushen Expressway underpassing the Qin Great Wall ruins and pointed out that the shallow-buried underexcavation method can effectively restrain the deformation of the surrounding rock. It has the advantage of controlling ground subsidence. Yu [12] studied the influence of different excavation procedures, excavation methods, and buried depth of shallow-buried excavation method on the ground settlement above the excavation boundary based on the model test method with the background of Shenzhen undercrossing Longgang ramp project. Li et al. [13] focused on the control of stratum deformation, starting with the concept of reducing, blocking, and controlling stratum deformation, and proposed safety control measures for the construction of the underpassing building project between the Cuobuling Station and Qingjiang Road Station of Qingdao Metro Line 3. In addition, scholars have also established a variety of analysis models for the ground subsidence caused by tunnel construction [14-16] and proposed feasible control measures [17-20].

The above research expounded the law of land subsidence and surrounding rock deformation caused by tunnel proximity construction and played a positive role in guiding the actual engineering construction. However, most of them 
are in the case of single hole or separated double hole, lacking the case of small spacing tunnel with more significant influence for reference. Based on the reconstruction project of the G220 Dongshen Line from Changqing Chenzhuang to Pingyin-Dongfeng Aqueduct Tunnelwhich underpasses through the cultural relic Dongfeng Aqueduct, this paper conducts a specific study on the construction method of the small clear tunnel underneath the existing cultural relics. It is hoped to ascertain the impact of the underpass construction of the new tunnel project on the existing cultural relics and propose reasonable construction control methods to ensure the safety of the existing sensitive buildings [21].

\section{Engineering Situations}

The Dongfeng Aqueduct Tunnel is a reconstruction project from Changqing Chenzhuang to Pingyin boundary section of the G220 Dongshen Line. It is specially designed for the Dongfeng Aqueduct to penetrate the cultural relics. Taking into account the distribution and structural characteristics of the existing cultural relics, the tunnel is designed as two left and right. The mileages of both the left and the right lines are $\mathrm{K} 288+608 \sim \mathrm{K} 288+658$. The length is $50 \mathrm{~m}$, and the clear distance between the tunnels is about $6 \mathrm{~m}$, which is a short tunnel with a small clear distance. The positional relationship between the Dongfeng Aqueduct Tunnel and the existing cultural relic Dongfeng Aqueduct is shown in Figure 1.

Dongfeng Aqueduct was built in 1970. It is an important part of Xiaoli Dongfeng Irrigation Station and Dongfeng Aqueduct, the fourth batch of municipal cultural relic protection units in Jinan. The aqueduct spans National Highway 220 and Ji-He Expressway, connecting the east and west sides of the mountain slopes, with a total of 34 holes and stone arch structure. The main span is $11.08 \mathrm{~m}$, and the side span is $6.75 \sim 6.8 \mathrm{~m}$. The buried depth of the aqueduct pier foundation is $1.3 \sim 2 \mathrm{~m}$. The proposed Dongfeng Aqueduct tunnel passes through the main span of the aqueduct (crossing angle: $77^{\circ}$ ). The left-line tunnel passes under pier 2, and the right-line tunnel passes under pier 3 and pier 4 . The aqueduct above the tunnel is $16.2 \mathrm{~m}$ high, and the vault is $13.2 \mathrm{~m}$ away from the pavement. The buried depth of the tunnel is about $7 \mathrm{~m}$, as shown in Figure 1 .

According to the relevant content of Code for design of irrigation and drainage system buildings (SL482-2011) and the purpose of protecting cultural relics, the settlement control of the aqueduct pier in the cross section in this project was carried out based on the settlement control standard used on the operation period. The allowable maximum settlement of the aqueduct pier structure is $20 \mathrm{~mm}$, and the allowable maximum settlement difference of the adjacent pier is $10 \mathrm{~mm}$.

\section{Design and Construction Scheme}

According to engineering geological mapping and exploration, the stratum of the tunnel site is the quaternary residual slope deposit and the Cambrian shale, limestone and marl thin layer. The hydrogeology is simple, and the surrounding rock conditions of Dongfeng Aqueduct tunnel are classified as $\mathrm{V}$ grade surrounding rock by comprehensive geological parameters, as shown in Figure 2.

Furthermore, comprehensively considering the terrain and geology of the intersection of G220 Dongshen Line with Dongfeng Aqueduct and the existing design experience, the proposed tunnel lining structure is a three-center circular curved wall structure. The supporting parameters are shown in Figure 2. At the same time, in order to solve the settlement control of shallow tunnel construction in sensitive environments and to avoid the uneven settlement exceeding the limit value of the foundation of the Dongfeng Aqueduct in the cross section after tunnel excavation, the $40 \mathrm{~m}$ long $\varphi 152 \mathrm{~mm}$ advanced large pipe shed was planned to be used for prereinforcement in the tunnel undercrossing section. Besides, the CRD method and the cantilever roadheader excavation method are adopted, as shown in Figure 3. The specific construction techniques are as follows:

(1) Surface Grouting Reinforcement. In order to improve stratum stability, surface grouting reinforcement should be carried out within the influence range of aqueduct. The grouting pipe is a seamless steel pipe with a diameter of $42 \mathrm{~mm}$ and a wall thickness of $4 \mathrm{~mm}$, and the steel bar with a diameter of $8 \mathrm{~mm}$ is welded as the stiffening hoop. The spacing between grouting pipes was $100 \mathrm{~cm}$, the plum-shaped arrangement was adopted for the longitudinal spacing of $100 \mathrm{~cm}$, as shown in Figure 3. The slurry used for grouting is cement-water glass slurry, which is blended strictly in accordance with the cement slurry water-cement ratio of $0.8: 1$. Water glass is $5 \%$ of the cement weight. The grouting pressure is strictly controlled according to the actual situation during grouting.

(2) Pipe Shed Construction. Firstly, the aqueduct is temporarily reinforced with full framing, and then the large pipe shed is constructed. The pipe shed is $40 \mathrm{~m}$ long, the diameter is $152 \mathrm{~mm}$, and the wall thickness is $6 \mathrm{~mm}$. Two rows of $\varphi 12 \mathrm{~mm}$ plum blossom-shaped grouting holes are drilled around. The elevation angle of pipe shed $\left(1^{\circ}\right)$ is parallel to the middle line of the route, as shown in Figure 4.

(3) Mechanical Excavation of Main Tunnel by CRD Method. The main tunnel is excavated by CRD method + cantilever roadheader, and the left and right tunnels are excavated separately. The excavation sequence is strictly observed and the footage is controlled. First, the small duct advance support of the right main tunnel is carried out. After the advance support, the upper bench of the right pilot tunnel is excavated. Initial support is provided promptly after excavation. Secondly, the excavation and initial support of the lower stage of the right pilot tunnel are carried out. At the same time of the initial 


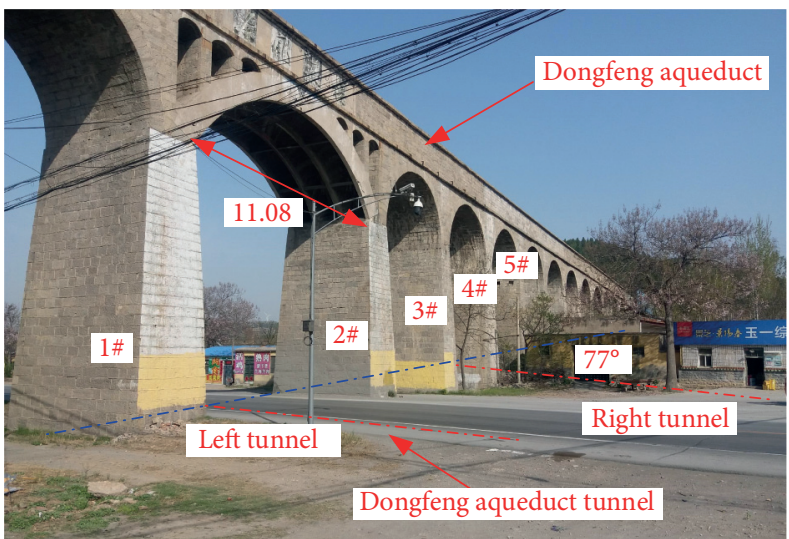

(a)

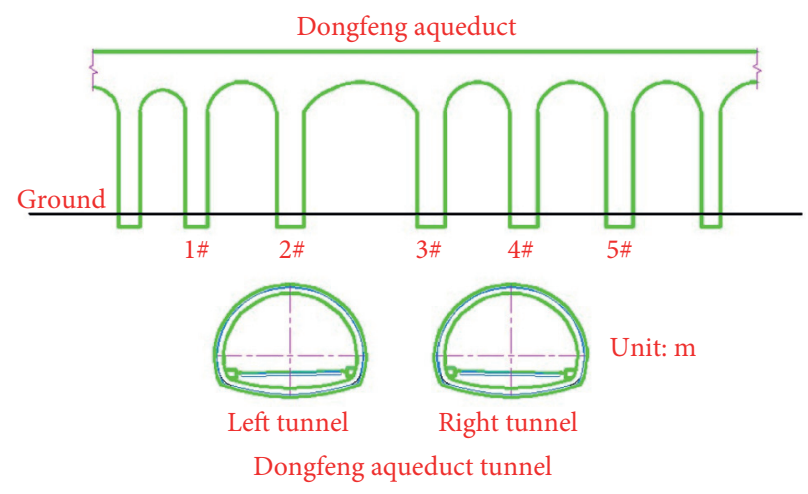

(b)

Figure 1: Location map of Dongfeng Aqueduct tunnel: (a) spatial position; (b) facade.

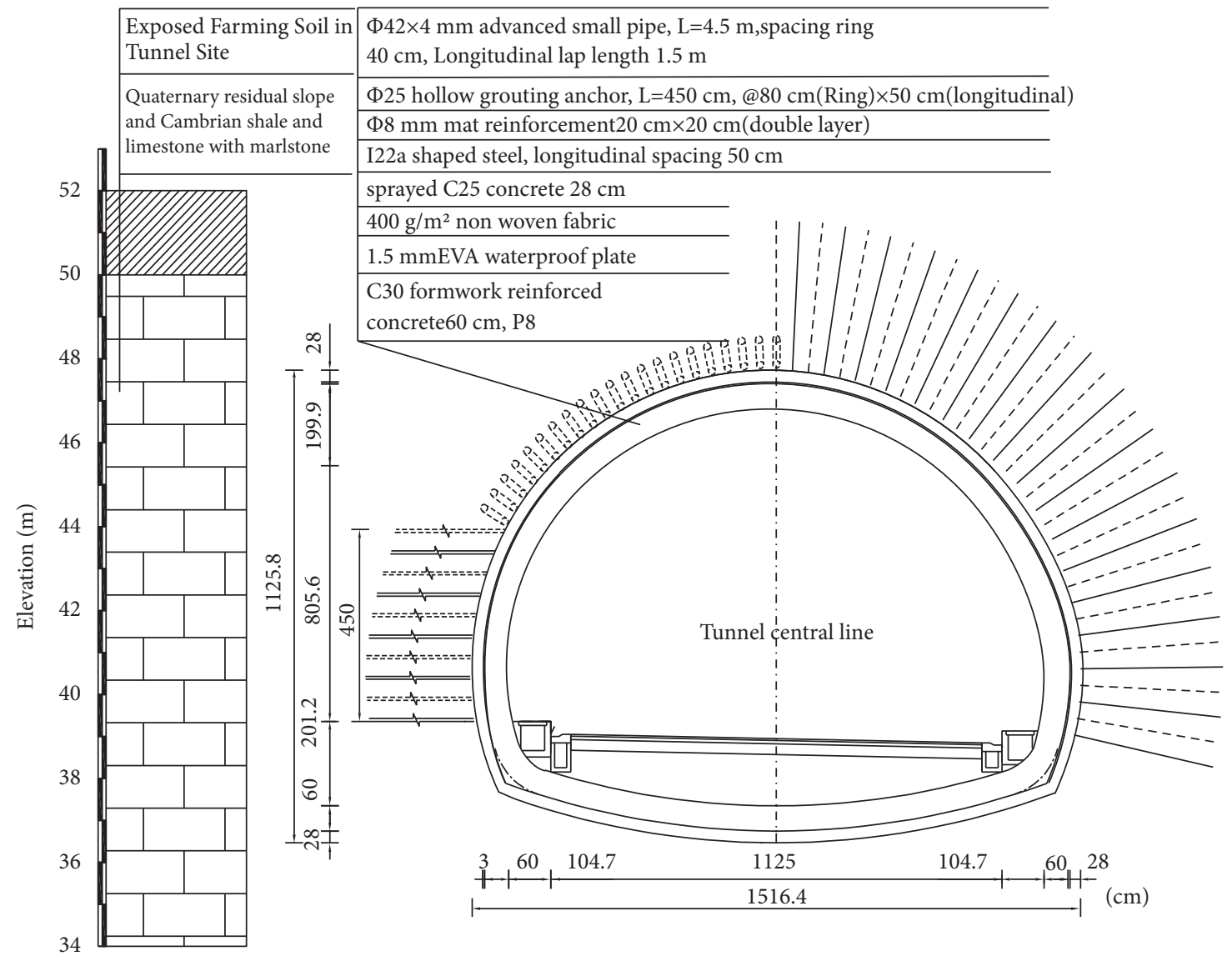

Figure 2: Geological conditions of tunnel site and section map of tunnel design.

support, a small grouting pipe is set up for the middle rock column to reinforce the middle rock. In the same way, the left pilot hole was excavated, as shown in Figure 5. After the initial support of the left pilot tunnel was completed, temporary support should be removed, and inverted arch and secondary lining were applied. The right tunnel adopts the same construction method.

\section{Feasibility Analysis of the Scheme}

In order to accurately analyze the influence of new tunnel undercrossing construction on Dongfeng Aqueduct and master the surrounding surface settlement law induced by tunnel excavation, seven span piers which have the greatest influence on the aqueduct in the process of tunnel excavation were selected as the research objects. The finite 


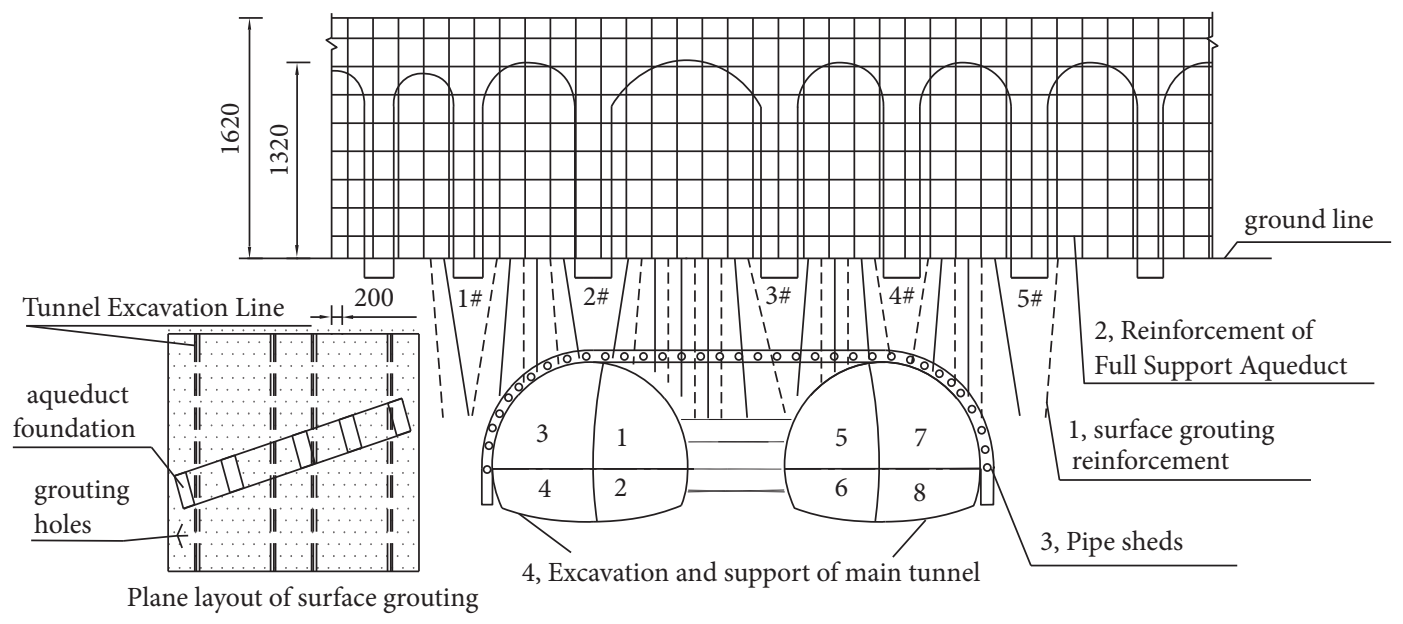

Figure 3: Excavation scheme of Dongfeng Aqueduct tunnel $(\mathrm{cm})$.

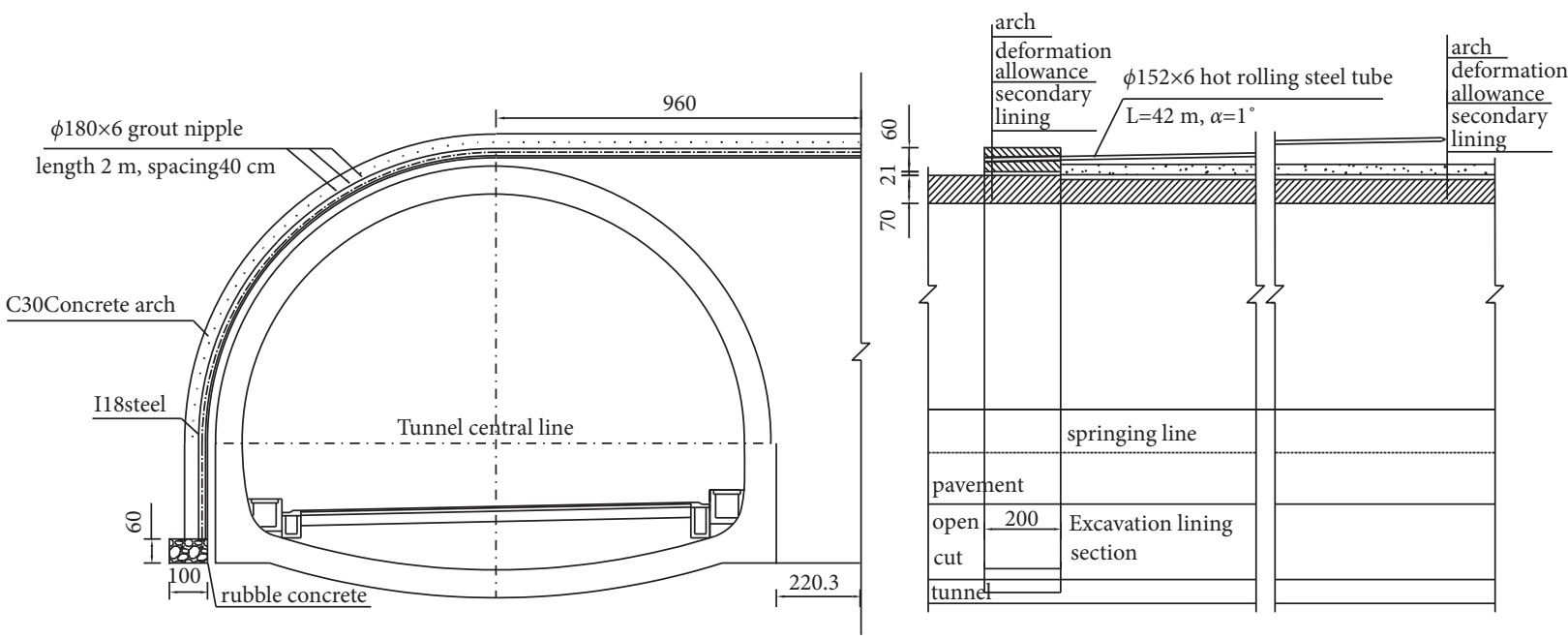

Figure 4: Pipe roof structure diagram $(\mathrm{cm})$.

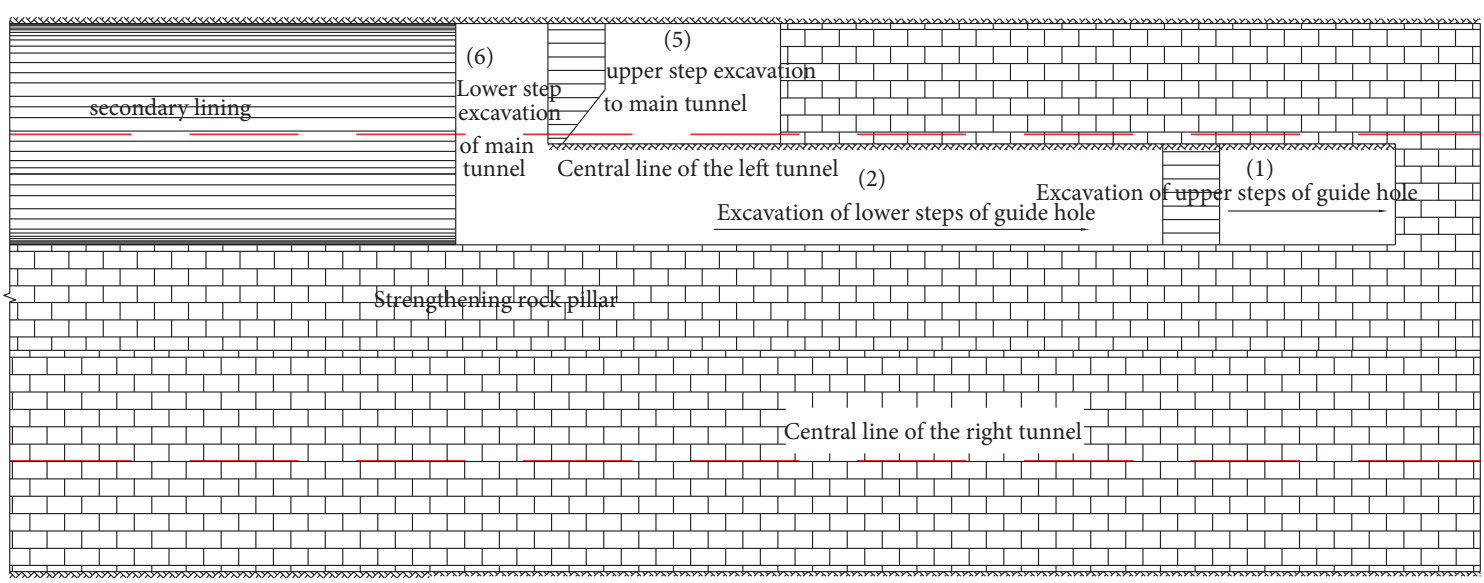

Figure 5: Excavation step diagram.

element model was established to investigate the influence of tunnel excavation on its deformation and internal force, and then the safety influence of tunnel undercrossing construction on the aqueduct was evaluated.
4.1. Modeling. In combination with the actual situation of the project, the left and right sides and the lower boundary of the model tunnel in the horizontal direction were all three times the diameter of the tunnel, and the left and right sides 


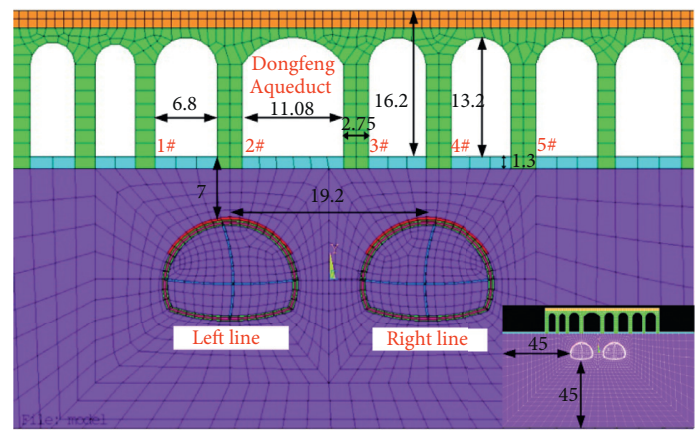

Figure 6: Calculation model (m).

TABLE 1: Values of calculation parameters for aqueduct structure.

\begin{tabular}{|c|c|c|c|c|c|c|}
\hline Name & $\begin{array}{l}\text { Elastic modulus } \\
\qquad(\mathrm{GPa})\end{array}$ & $\begin{array}{l}\text { Poisson's } \\
\text { ratio }\end{array}$ & $\begin{array}{l}\text { Volumetric weight } \\
\qquad\left(\mathrm{kN} / \mathrm{m}^{3}\right)\end{array}$ & $\begin{array}{c}\text { Shear transfer coefficient } \\
\text { of open cracks }\end{array}$ & $\begin{array}{c}\text { Shear transfer coefficient } \\
\text { of closed cracks }\end{array}$ & $\begin{array}{c}\text { Uniaxial } \\
\text { tensile } \\
\text { stress }(\mathrm{MPa})\end{array}$ \\
\hline $\begin{array}{l}\text { Flume } \\
\text { structure }\end{array}$ & 20000 & 0.25 & 25 & 0.35 & 0.9 & 0.75 \\
\hline
\end{tabular}

TABLE 2: Calculation parameters of surrounding rock.

\begin{tabular}{lcccc}
\hline Surrounding rock & Modulus of deformation (MPa) & $\begin{array}{c}\text { Poisson's ratio } \\
\text { Quaternary residual slope deposit }\end{array}$ & $\begin{array}{c}\text { Volumetric weight } \\
\left(\mathrm{kN} / \mathrm{m}^{3}\right)\end{array}$ & $\begin{array}{c}\text { Friction angle }\left({ }^{\circ}\right) \\
(\mathrm{MPa})\end{array}$ \\
\hline Medium weathered marlstone & 15 & 0.37 & 18 & 15 \\
Advanced pipe shed & 3800 & 0.31 & 22 & 0.03 \\
& 20000 & 0.25 & 24 & 35 \\
\hline
\end{tabular}

of the aqueduct were symmetrical boundaries. The numerical model is shown in Figure 6.

4.2. Calculation Parameters. Since the aqueduct was built of reinforced concrete and mortar block stones, the strength of the joint mortar is lower than that of block stones and concrete. Besides, the aqueduct was built early, and its materials had different degrees of deterioration. When establishing the continuum model, its structural material adopts the concrete constitutive model. The material parameters of the aqueduct structure are shown in Table 1.

The surrounding rock adopts the Drucker-Prager constitutive model, and the supporting effect of the advanced pipe roof on the surrounding rock was considered by increasing the surrounding rock parameters, as shown in Table 2. The parameter values of the temporary support, initial support, and secondary lining of the tunnel are shown in Table 3.

4.3. Calculating Procedure. The method used for tunnel excavation is the CRD method, and the whole process of underpassing the tunnel may have an impact on the aqueduct. Therefore, it is necessary to establish a separate analysis step for each excavation step to consider. There were a total of 22 analysis steps in the calculation and analysis steps of this model. The general steps are as follows: step 1 -initial stress field balance; step 2-soil reinforcement; steps 3-12-from left tunnel presupporting to completion of construction; and steps 13-22-from right tunnel presupporting to completion.

4.4. Result Analysis. Figures 7 10 show the calculation results of the deformation and force of each key part after the excavation of the Dongfeng Aqueduct tunnel. The analysis shows the following:

(1) After the excavation of the left tunnel, the surrounding rock and the upper aqueduct structure were deformed. However, due to the support effect of pipe roof and tunnel structure, the influence range of surrounding rock deformation was small. The deformation of aqueduct structure mainly occurred near No. 1 and No. 2 piers above the roof of the tunnel, as shown in Figure 7(a). After the excavation of both left and right tunnels, the influence range of surrounding rock deformation was further increased. The structural deformation of aqueduct mainly occurred in the range of piers $1-5$ above the top of the tunnel, as shown in Figure 7(b). Through the deformation results of aqueduct structure, it can be found that during tunnel excavation, the deformation of the aqueduct is mainly vertical settlement with a slight twist, as shown in Figure 8 . The settlement of aqueduct foundation was large above the vault and small on both sides. The settlement curve is 


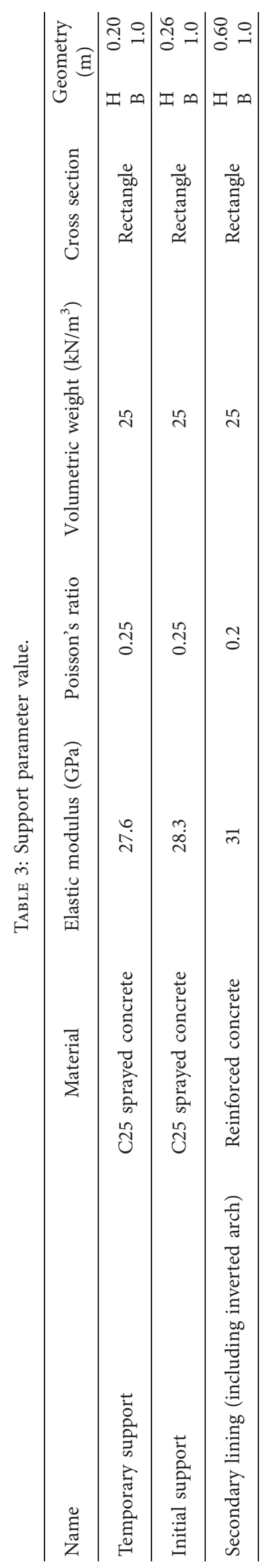




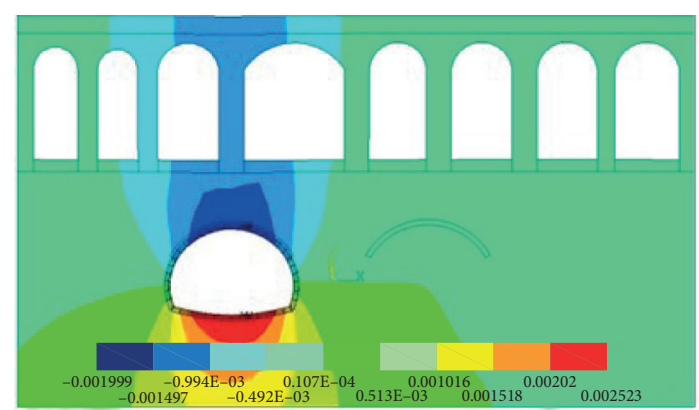

(a)

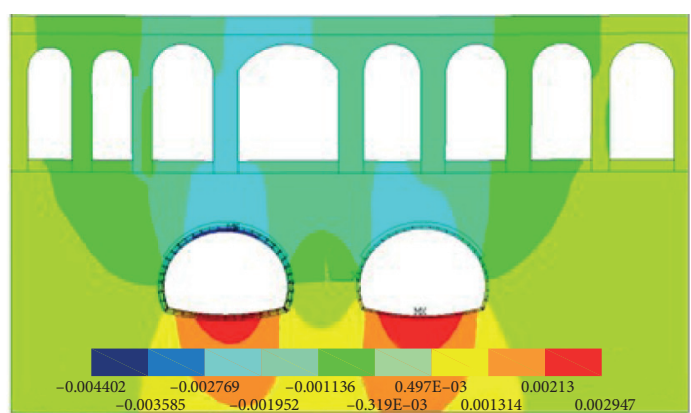

(b)

Figure 7: Overall vertical deformation of the model. (a) After the excavation of the left tunnel. (b) After the excavation of the right tunnel.

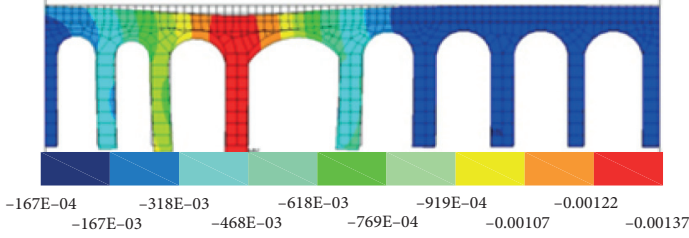

(a)

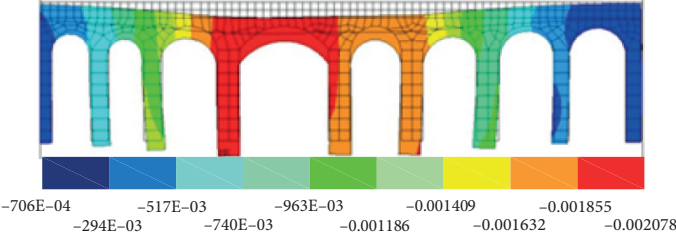

(b)

FIGURE 8: Structural deformation of aqueduct. (a) After the excavation of the left tunnel. (b) After the excavation of the right tunnel.

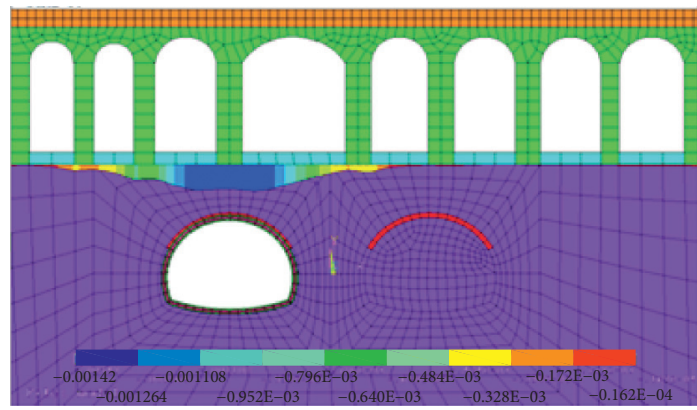

(a)

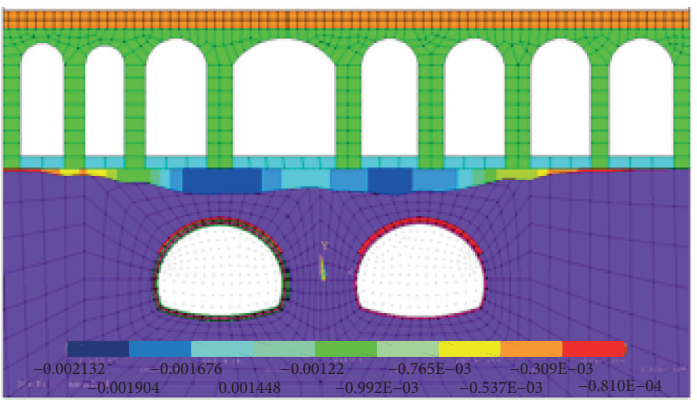

(b)

FIGURE 9: Settlement of aqueduct foundation. (a) After the excavation of the left tunnel. (b) After the excavation of the right tunnel.

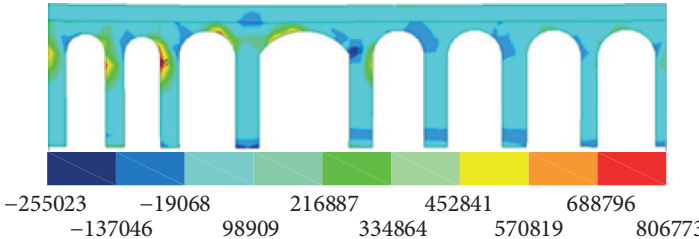

(a)

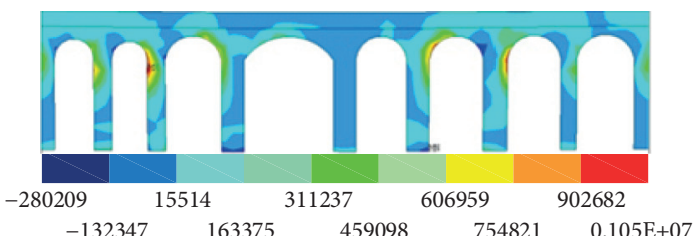

(b)

Figure 10: First principal stress of aqueduct structure. (a) After the excavation of the left tunnel. (b) After the excavation of the right tunnel.

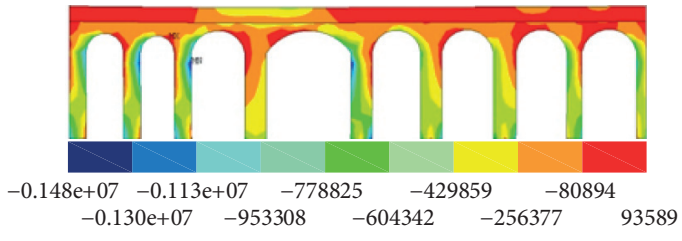

(a)

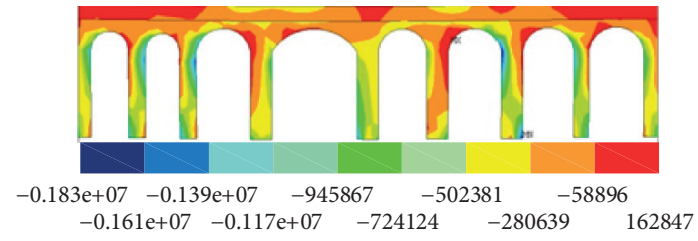

(b)

FIgURE 11: Third principal stress of aqueduct. (a) After the excavation of the left tunnel. (b) After the excavation of the right tunnel. 


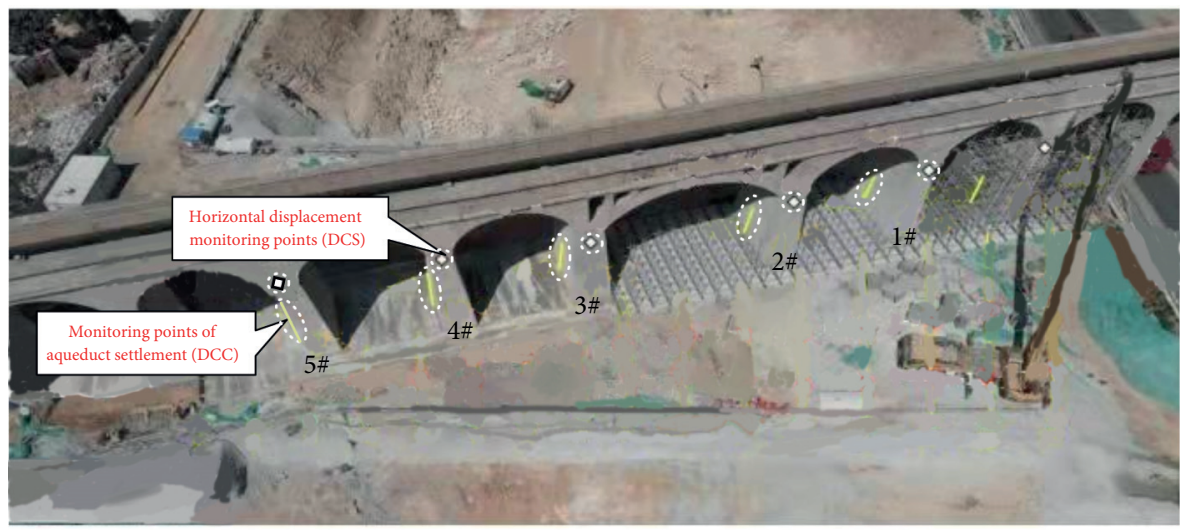

FIGURE 12: Measuring point layout.

"W" shaped. The maximum calculation value of foundation differential settlement was about $7 \mathrm{~mm}$, as shown in Figure 9.

(2) The stress of aqueduct structure was redistributed locally under deformation. After the left line excavation was completed, local tensile stress appeared near the arch ring connected with pier 1 and pier 2. The direction of tensile stress was basically tangent to the arch ring, and the maximum tensile stress was $0.57 \sim 0.81 \mathrm{MPa}$. After the excavation of the left and right lines, local tensile stress appeared near the arch ring connected with piers $1 \sim 5$, and the maximum tensile stress was in the range of $0.6 \sim 1.1 \mathrm{MPa}$ (Figures 10 and 11). The maximum tensile stress was lower than the bending tensile strength of stone and was greater than the strength of masonry cement mortar. Therefore, under the influence of tunnel construction, the aqueduct structure may have small range of masonry cracks. However, the tensile stress was mainly concentrated near the surface of the structure, the scale was small, the structure was not connected, and the internal stress of the structure was still dominated by compressive stress. Therefore, the masonry crack mainly occurs on the surface of the structure, which is not easy to develop into the internal structure and has little influence on the bearing capacity of the structure. So, it can be considered that the aqueduct structure was still in a safe state.

\section{Engineering Application Effect}

During the implementation of this project, measuring points were arranged on piers 1 to 5 to monitor the cumulative vertical displacement of aqueduct foundation. The arrangement of measuring points is shown in Figure 12, and the monitoring results of representative measuring points are shown in Figure 13. The analysis shows the following:

(1) The vertical displacement of aqueduct foundation generally showed a cumulative growth trend, except for a slight uplift in the period of surface grouting and pipe shed construction stage. In the presupport stage, the change of vertical displacement of foundation is relatively obvious, and in the left and right tunnel excavation stages, the vertical displacement gradually tended to be stable. In the process of slope construction, the cumulative vertical displacement of each measuring point was not large, and the maximum vertical displacement occurs in No. 2 foundation of $-1.5 \mathrm{~mm}$. The maximum value of cumulative vertical displacement in surface grouting engineering was $-3.6 \mathrm{~mm}$ in foundation 3 . The maximum cumulative vertical displacement of pipe shed during construction was $-5.5 \mathrm{~mm}$ in No. 3 foundation. In the process of left and right tunnel excavation, the maximum cumulative vertical displacement also appeared in No. 3 foundation of $-6.1 \mathrm{~mm}$. In the construction process, the maximum differential settlement was $5.2 \mathrm{~mm}$. It can be seen that in the process of presupport, the vertical displacement of aqueduct structure foundation was in a reasonable range and the differential settlement was also in the specified range.

(2) The horizontal displacement of aqueduct foundation generally showed a trend of cumulative shrinkage, with the exception of foundation No. 4 and foundation No. 5 slightly expanding in the period of surface grouting and pipe shed construction stage. In the presupport stage, the horizontal displacement of foundation changes significantly, and in the left and right tunnel excavation stages, the horizontal displacement gradually tended to be stable. In the process of slope construction, the cumulative horizontal displacement of each measuring point was not large, and the maximum horizontal displacement occurred in No. 3 foundation of $-1.7 \mathrm{~mm}$. The maximum value of cumulative horizontal displacement in surface grouting engineering was $-3.1 \mathrm{~mm}$ in foundation 2 . The maximum cumulative horizontal displacement during pipe shed construction appears on foundation No. 2 of $-4.2 \mathrm{~mm}$. In the process of left and right tunnel excavation, the 


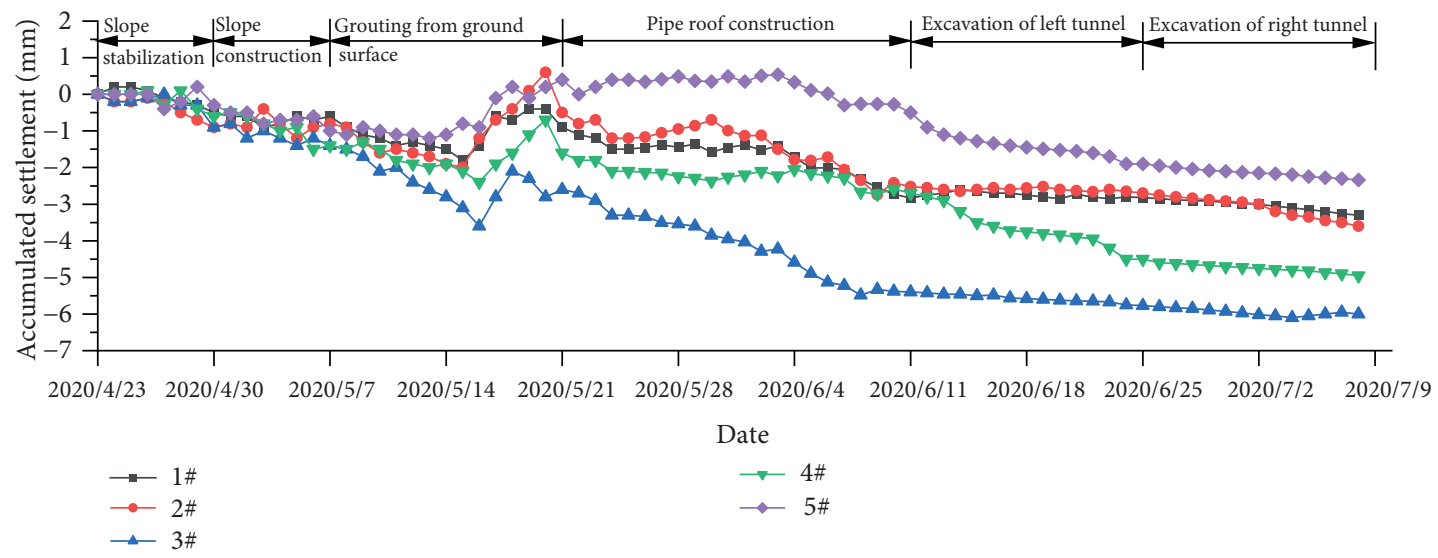

(a)

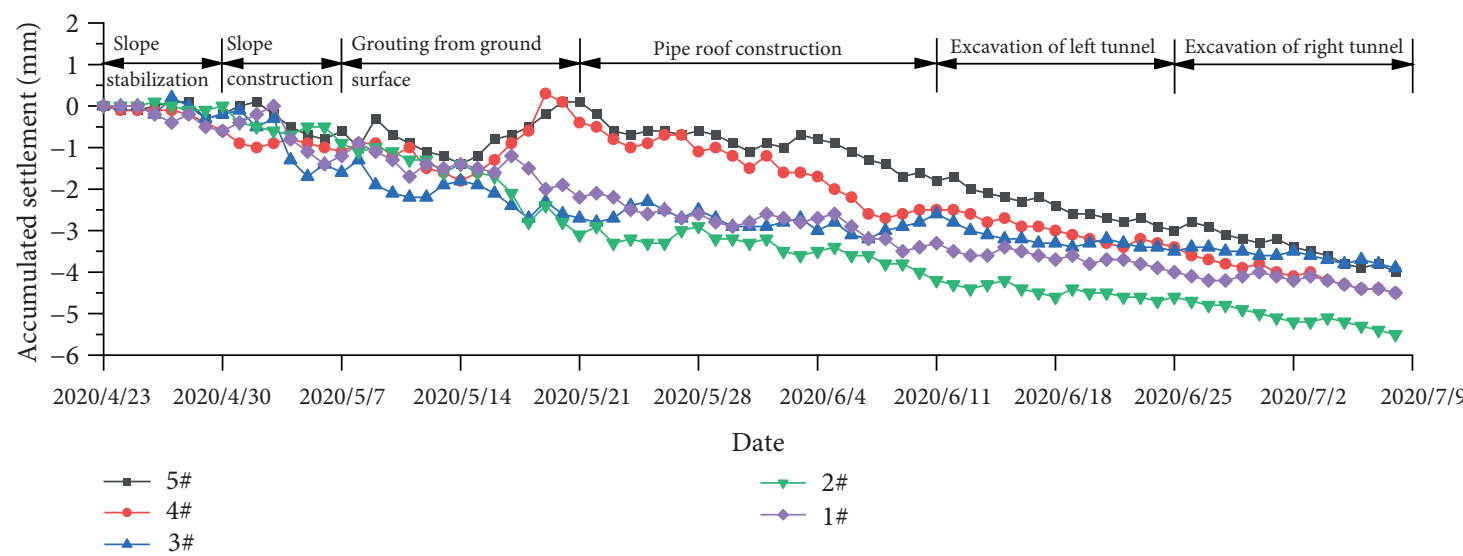

(b)

Figure 13: Monitoring data of representative measuring points. (a) Cumulative settlement map. (b) Cumulative horizontal displacement map (+: outward expansion; -: draw-in).

maximum cumulative horizontal displacement also appeared in No. 2 foundation of $-5.5 \mathrm{~mm}$. The $\mathrm{cu}^{-}$ mulative horizontal displacement of each foundation during construction was also less than the warning value of $20 \mathrm{~mm}$. It can be seen that in the presupport process, the horizontal displacement of the aqueduct structure foundation was in a reasonable range.

\section{Conclusion}

(1) Based on the reconstruction project of the section from Chenzhuang to Pingyin on the Dongshen line of G220, a special tunnel structure and construction plan design is carried out. The comprehensive deformation control scheme of "CRD single-arm tunneling + surface grouting prereinforcement + advanced large pipe shed presupport" is proposed, and the corresponding design parameters were obtained. This case can be used as reference for similar projects.

(2) The numerical simulation of mechanical behavior in the whole process of reinforcement treatment and excavation construction of Dongfeng Aqueduct tunnel was carried out. The results showed that the comprehensive deformation control scheme proposed by the project can ensure the safety of the existing construction, and the stratum deformation caused by the excavation of the new tunnel was small, which meets the requirements of safety prevention and control.

(3) The field monitoring scheme of the whole construction process was formulated and the real-time tracking observation was carried out. The results showed that the cumulative vertical displacement of the aqueduct foundation increases first, then decreases and increases again, and finally tends to be stable. The vertical displacement of the measuring point on the basis of No. 3 was the most significant, and the maximum value is $-6.1 \mathrm{~mm}$. The cumulative horizontal displacement of aqueduct foundation generally increased slowly except No. 4 and No. 5 . From the completion of surface grouting to the pipe shed construction stage, the horizontal displacement was basically stable at other measuring points except for the expansion of foundation No. 4 and No. 5. The maximum cumulative horizontal displacement of No. 2 measuring point was $-5.5 \mathrm{~mm}$. 


\section{Data Availability}

The data used to support the findings of this study are available from the corresponding author upon request.

\section{Conflicts of Interest}

The authors declare that they have no conflicts of interest.

\section{Acknowledgments}

This study was funded by the Transportation Department Science and Technology Research Project of Shandong Province, China (no. 2019B55).

\section{References}

[1] C. Zhao, M. Lei, C. Shi, H. Cao, W. Yang, and E. Deng, "Function mechanism and analytical method of a double layer pre-support system for tunnel underneath passing a largescale underground pipe gallery in water-rich sandy strata: a case study," Tunnelling and Underground Space Technology, vol. 115, Article ID 104041, 2021.

[2] M. Lei, D. Lin, Q. Huang, C. Shi, and L. Huang, "Research on the construction risk control technology of shield tunnel underneath an operational railway in sand pebble formation: a case study," European Journal of Environmental and Civil Engineering, vol. 24, no. 10, pp. 1558-1572, 2020.

[3] M. Lei, L. Liu, C. Shi, Y. Tan, Y. Lin, and W. Wang, "A novel tunnel-lining crack recognition system based on digital image technology," Tunnelling and Underground Space Technology, vol. 108, Article ID 103724, 2021.

[4] Q. Tang, M. Lei, B. Zhu, L. Peng, W. Wu, and C. Shi, "Design and application of risk early warning system for subway station construction based on building information modeling real-time model," Advances in Civil Engineering, vol. 2021, pp. 1-12, Article ID 8898893, 2021.

[5] L. Huang, J. Ma, M. Lei, L. Liu, Y. Lin, and Z. Zhang, "Soilwater inrush induced shield tunnel lining damage and its stabilization: a case study," Tunnelling and Underground Space Technology, vol. 97, Article ID 103290, 2020.

[6] J. Liu, C. Shi, M. Lei, Z. Wang, C. Cao, and Y. Lin, "A study on damage mechanism modelling of shield tunnel under unloading based on damage-plasticity model of concrete," Engineering Failure Analysis, vol. 123, Article ID 105261, 2021.

[7] M. Lei, J. Li, C. Zhao, C. Shi, W. Yang, and E. Deng, "Pseudodynamic analysis of three-dimensional active earth pressures in cohesive backfills with cracks," Soil Dynamics and Earthquake Engineering, vol. 150, Article ID 106917, 2021.

[8] M. Lei, B. Zhu, C. Gong, W. Ding, and L. Liu, "Sealing performance of a precast tunnel gasketed joint under high hydrostatic pressures: site investigation and detailed numerical modeling," Tunnelling and Underground Space Technology, vol. 115, Article ID 104082, 2021.

[9] Q. Tang, F. Chen, M. Lei, B. Zhu, and L. Peng, "Study on the generalized displacement boundary and its analytical prediction for ground movements induced by shield tunneling," Advances in Civil Engineering, vol. 2021, Article ID 8858874, 18 pages, 2021.

[10] J. Liu, C. Shi, M. Lei, C. Cao, and Y. Lin, "Improved analytical method for evaluating the responses of a shield tunnel to adjacent excavations and its application," Tunnelling and Underground Space Technology, vol. 98, Article ID 103339, 2020.
[11] Y. Wang, "Scheme comparison and settlement control of shallow-buried double-span and large-section rectangular tunnel under the Great Wall site," Sichuan Architecture, vol. 33, no. 03, pp. 163-166, 2013, in Chinese.

[12] X. Yu, Model Test Study on Urban Shallow-Buried Underground Tunnel Crossing Existing Bridge Piles, Dalian University of Technology, 2019, in Chinese.

[13] Y. Li, D. Zhang, F. A. N. G. Qian et al., "Study on safety control technology of upper building crossed by shallow metro tunnel," Journal of Civil Engineering, vol. 48, no. S1, pp. 266-269, 2015, in Chinese.

[14] C. Camós and C. Molins, "3D analytical prediction of building damage due to ground subsidence produced by tunneling," Tunnelling and Underground Space Technology, vol. 50, pp. 424-437, 2015.

[15] D. Wu, T. Deng, R. Zhao, and Y. Wang, "THM modeling of ground subsidence induced by excavation of subway tunnel," Computers and Geotechnics, vol. 94, pp. 1-11, 2018.

[16] C. D. Garner and R. A. Coffman, "Subway tunnel design using a ground surface settlement profile to characterize an acceptable configuration," Tunnelling and Underground Space Technology, vol. 35, pp. 219-226, 2013.

[17] H. Cao, L. Peng, M. Lei, Q. Tang, L. Peng, and F. Chen, "Calculation model of supporting system for tunnel under shallow and weak surrounding rock considering the synergistic effects," Geotechnical \& Geological Engineering, vol. 38, no. 2, pp. 1379-1388, 2020.

[18] J. Liu, C. Shi, C. Cao, M. Lei, and Z. Wang, "Improved analytical method for pile response due to foundation pit excavation," Computers and Geotechnics, vol. 123, Article ID 103609, 2020.

[19] C. Liu, M.-f. Lei, L.-m. Peng, and C.-h. Shi, "Cavity influence on fatigue performance of heavy haul railway Tunnel's bottom structure," Construction and Building Materials, vol. 251, Article ID 118886, 2020.

[20] Y. Cui, K. Kishida, and M. Kimura, "Prevention of the ground subsidence by using the foot reinforcement side pile during the shallow overburden tunnel excavation in unconsolidated ground," Tunnelling and Underground Space Technology, vol. 63, pp. 194-204, 2017.

[21] C. Jia, Q. Zhang, M. Lei, Y. Zheng, J. Huang, and L. Wang, "Anisotropic properties of shale and its impact on underground structures: an experimental and numerical simulation," Bulletin of Engineering Geology and the Environment, vol. 80, 2021. 